\title{
SLC11A1 (formerly NRAMP1) and susceptibility to visceral leishmaniasis in The Sudan
}

Hiba Salah Mohamed ${ }^{1,2}$, Muntaser Eltayeb Ibrahim ${ }^{1}$, Elinor Nancy Miller ${ }^{2}$, Jacqueline Katie White $^{2}$, Heather Jane Cordell ${ }^{2}$, Joanna McCammond McGill Howson ${ }^{2}$, Christopher Sean Peacock $^{2}$, Eltahir Awad Gasim Khalil ${ }^{1}$, Ahmed Mohamed El Hassan ${ }^{1}$ and Jenefer Mary Blackwell*,2 $^{*}$

${ }^{1}$ Institute of Endemic Diseases, University of Khartoum, Khartoum, Sudan; ${ }^{2}$ Cambridge Institute for Medical Research, Wellcome Trust/MRC Building, University of Cambridge School of Clinical Medicine, Addenbrooke's Hospital, Hills Road, Cambridge CB2 2XY, UK

Genetic susceptibility to visceral leishmaniasis (VL) is indicated by differences in incidence and clinical phenotypes between ethnic groups in Sudan. In mice, innate susceptibility to Leishmania donovani, the etiological agent of $\mathrm{VL}$, is controlled by S/c11a1 (formerly Nramp1). We therefore examined polymorphisms at SLC11A1 in 59 multicase families of VL from the high-incidence Masalit tribe in Sudan. Multipoint nonparametric analysis in ALLEGRO shows a significant linkage across SLC11A1 ( $Z_{\text {Ir }}$ Scores 2.38$2.55 ; 0.008 \leqslant P \leqslant 0.012$; information content 0.88 ). The extended transmission disequilibrium test shows biased transmission of alleles at $5^{\prime}$ polymorphisms in the promoter $(P=0.0145)$, exon $3(P=0.0037)$ and intron $4(P=0.0049)$, and haplotypes formed by them $(P=0.0089)$, but not for $3^{\prime}$ polymorphisms at exon 15 or the $3^{\prime}$ UTR. Stepwise logistic regression analysis using a case/pseudo-control data set derived from the 59 families was consistent with main effects contributed by the intron $4469+14 \mathrm{G} / \mathrm{C}$ polymorphism. Although the two alleles for $469+14 \mathrm{G} / \mathrm{C}$ lie on haplotypes carrying different alleles for the functional promoter $\mathrm{GT}_{n}$ polymorphism, the latter did not itself contribute separate main effects. Sequence analysis of 36 individuals failed to identify new putative functional polymorphisms in the coding region, intron 1, intron/exon boundaries, intron 4/exon $4 a$, or in the $3^{\prime} U T R$. One novel promoter polymorphism $(-86 G / A)$ was located within a putative nuclear factor kappa B binding site that could be functional. Further work will determine whether additional polymorphisms occur upstream in the promoter, which could be in linkage disequilibrium with the intron 4 polymorphism. These studies contribute to knowledge of the role of SLC11A1 in infectious disease.

European Journal of Human Genetics (2004) 12, 66-74. doi:10.1038/sj.ejhg.5201089

Published online 1 October 2003

Keywords: leishmaniasis; SLC11A1 (=NRAMP1); linkage; association

Introduction

The current outbreak of kala-azar or clinical visceral leishmaniasis (VL) caused by Leishmania donovani sensu strictu in eastern and southern Sudan has taken its toll in an

*Correspondence: Prof. JM Blackwell. Tel: + 441223 336947;

Fax: + 441223 331206; E-mail: jennie.blackwell@cimr.cam.ac.uk Received 13 March 2003; accepted 1 August 2003 impoverished, war-stricken population, killing tens of thousands and depopulating vast areas of southern Sudan. The calamity brought kala-azar to the forefront as one of the greatest epidemics of the 20th century. ${ }^{1,2}$ Longitudinal studies in Sudan show marked differences in incidence of clinical disease between adjacent villages inhabited by different ethnic groups. ${ }^{3,4}$ Furthermore, when members of the different ethnic groups share the same immediate 
environment and exposure, certain ethnic groups remain at a higher risk of developing VL. ${ }^{5}$ These observations support the hypothesis that the host genotype plays an important role in disease susceptibility.

VL caused by $L$. donovani sensu strictu in the mouse provides a classical model of major single gene control of innate resistance to infection. ${ }^{6-10}$ The gene, designated $L s h$, Ity or $B c g$, was also shown to influence innate resistance to Salmonella typhimurium, ${ }^{11-13}$ Mycobacterium bovis BCG,${ }^{14} \mathrm{M}$. lepraemurium $^{15,16}$ and $M$. intracellulare. ${ }^{17}$ Following its identification by positional cloning, ${ }^{18}$ the gene was renamed the natural resistance-associated macrophage protein (Nramp1). This is now superseded by the functional designation solute carrier family 11a (proton-coupled divalent metal ion transporters) member 1 or Slc11a1, consistent with our formal demonstration that the proteins encoded by Slc11a1/SLC11A1 function as proton/divalent cation $\left(\mathrm{Fe}^{2+}, \mathrm{Zn}^{2+}\right.$ and $\left.\mathrm{Mn}^{2+}\right)$ antiporters. ${ }^{19}$ Mice carrying the natural gly-to-asp mutation at position 169 in putative membrane-spanning domain number 4 are as susceptible to infection with all the three groups of pathogen as gene disrupted ('knockout') mice. ${ }^{20}$ The protein localises to the late endosomal/lysosomal compartment of macrophages, ${ }^{21,22}$ but not to early endosomes. ${ }^{21}$ In man, SLC11A1 has been linked to genetic susceptibility to leprosy in Vietnam $^{23}$ and to tuberculosis in Brazil ${ }^{24}$ and in aboriginal Canadians. ${ }^{25}$ Indeed, SLC11A1 appears to be globally associated with tuberculosis, ${ }^{24-29}$ with evidence that both $5^{\prime}$ and $3^{\prime}$ polymorphisms contribute independently to susceptibility. ${ }^{26}$ Linkage or allelic association has also been demonstrated for HIV $^{30}$ and for a wide range of autoimmune diseases in man. ${ }^{31-37}$ Here, we present data demonstrating a role for SLC11A1 in determining susceptibility to VL in the highly susceptible Masalit tribe in Sudan.

\section{Subjects and methods}

\section{Ascertainment of families}

The study was carried out on the Nilosaharan-speaking Masalit population who migrated from western Sudan in the early-mid 1980s to occupy villages along the Rahad River in the heart of the endemic area in eastern Sudan. Epidemiological and demographic details relating to the study site are described in detail elsewhere. ${ }^{3,4,38,39}$ Multicase families with VL were ascertained from epidemiological and medical records of the Institute of Endemic Diseases. Diagnosis was made on the basis of clinical, parasitological and serological criteria, as described. ${ }^{3,39}$ Ethical approval for this study was obtained from the Ethical Committee of the University of Khartoum. Buccal swab DNA was prepared from 312 individuals from 59 extended multicase families (67 nuclear families) with one to six affected offspring per nuclear family (Table 1). Nuclear families with one case were always part of an extended multicase pedigree.
Table 1 Family structures for the 59 Masalit families collected from El Rugab and Um Salala villages in eastern Sudan

\begin{tabular}{lc}
\hline Families structure & Number \\
\hline No. of families & 59 \\
No. of nuclear families & 67 \\
Nuclear families with one affected sib & 9 \\
Nuclear families with two affected sibs & 28 \\
Nuclear families with three affected sibs & 20 \\
Nuclear families with four affected sibs & 8 \\
Nuclear families with five affected sibs & 1 \\
Nuclear families with six affected sibs & 1 \\
No. of affected offspring & 168 \\
No. of affected parents & 9 \\
Total no. of affected individuals & 177 \\
Total no. of individuals & 312 \\
\hline
\end{tabular}

Nuclear families with a single affected offspring were always part of an extended multicase pedigree.

\section{Genotyping}

Three SNPs within SLC11A1 (274C/T, 469+14G/C and D543N) were genotyped using the PCR primers, restriction enzymes and conditions described. ${ }^{40}$ The microsatellite $D 2 S 1471^{41}$ and the $(\mathrm{GT})_{n}$ repeat in the promoter region of SLC11A1 ${ }^{42}$ were PCR amplified using NED- and FAMlabelled forward primers, and PCR products analysed by electrophoresis on $6 \%$ polyacrylamide gels using an automated sequencer (model ABI377, Applied Biosystems) as previously described. ${ }^{37}$ Two insertion/deletion (IN/DEL) polymorphisms in the $3^{\prime} \mathrm{UTR}$ of $S L C 11 A 1^{40,43}$ were also typed using the automated sequencer. The $3^{\prime} \mathrm{UTR}$ TGTG polymorphism ${ }^{40}$ was amplified using FAM-labelled ( $5^{\prime}$ TAC CTG CAG TAG GGC CA $3^{\prime}$ ) and unlabelled (5' AAA CAG CAG GTC CCT AAA GC) primers. This yielded allele sizes of $393 \mathrm{bp}$ (allele 1) and $397 \mathrm{bp}$ (allele 2). The 3'UTR CAAA polymorphism ${ }^{43}$ was amplified using HEX-labelled $\left(5^{\prime}\right.$ CTC CAG TTT GGA GCC TGT GT $3^{\prime}$ ) and unlabelled (5' CTA GCG CAG CCA TGT GAT TA $3^{\prime}$ ) primers. This yielded allele sizes of $245 \mathrm{bp}$ (allele 1) and $250 \mathrm{bp}$ (allele 2). Microsatellites and IN/DELs were analysed using the computer software genescan and genotyper (Applied Biosystems). Allele frequencies for the polymorphisms used in this study are shown in Table 2.

\section{Linkage analysis}

Nonparametric linkage analysis was performed in ALLE$\mathrm{GRO}^{44}$ using the $S_{\text {pairs }}$ scoring function with 0.5 weighting to take account of differences in family size. ALLEGRO reports allele-sharing LOD scores and maximum $Z$ scores for the likelihood ratio $\left(Z_{\mathrm{lr}}\right)$. One-sided $P$-values associated with LOD and $Z_{\mathrm{Ir}}$ scores are used throughout. For multipoint analysis, genetic distances between markers were entered in cM calculated on the basis of the physical map distance $(1 \mathrm{Mb}=1 \mathrm{cM})$. The fraction of the total inheritance information extracted by the available marker data is indicated by the 'information content'. Simulations 
Table 2 Allele frequencies for SLC11A1 markers and D2S1471

\begin{tabular}{lccc}
\hline Marker & $\begin{array}{c}\text { No. of } \\
\text { alleles }\end{array}$ & Heterozygosity & Allele frequencies \\
\hline$(\mathrm{GT})_{n}$ & 4 & 0.394 & $0.008 ; 0.246 ;$ \\
& & & $0.738 ; 0.008$ \\
274C/T & 2 & 0.322 & $0.201 ; 0.799$ \\
$469+14 G / C$ & 2 & 0.212 & $0.880 ; 0.120$ \\
D543N & 2 & 0.211 & $0.120 ; 0.880$ \\
3'UTR TGTC $^{\prime}$ 2 & 2 & 0.305 & $0.188 ; 0.812$ \\
JUTR CAAA $^{\prime}$ 2S1471 & 2 & 0.450 & $0.501 ; 0.499$ \\
& 17 & 0.888 & $0.130 ; 0.008 ;$ \\
& & & $0.031 ; 0.199 ;$ \\
& & & $0.145 ; 0.078 ;$ \\
& & & $0.033 ; 0.122 ;$ \\
& & & $0.012 ; 0.052 ;$ \\
& & & $0.033 ; 0.082 ;$ \\
& & & $0.012 ; 0.004 ;$ \\
& & & 0.008 \\
\hline
\end{tabular}

performed in ALLEGRO using SLC11A1 marker information from this study demonstrated that the 59 families had $100 \%$ power to detect linkage up to a critical value equivalent to an allele-sharing LOD score $>3.95$ $(P<0.00001)$ for a gene with penetrances $7-61 \%,{ }^{45}$ controlling the underlying susceptibility to VL.

\section{Allelic association testing}

Family-based allelic association tests were performed using the $\mathrm{TDT}^{46}$ correcting for clustering at the nuclear family level and nonindependence between sibs using a robust sandwich estimator for the variance and the Wald $\chi^{2}$-test. Single-point and haplotype TDT were also performed using the ETDT ${ }^{47}$ implemented within TDTPHASE. ${ }^{48}$ Allelic and genotype associations, and relative risk estimates, were obtained by creating a 'case/pseudo-control' study, where the 'cases' comprise the genotypes of the affected offspring, and the 'controls' are the one to three other genotypes (depending on whether phase is known or inferred) which the affected offspring might have received from the parents. ${ }^{49}$ The relative risks were estimated using conditional logistic regression analysis, again employing robust variance estimates to control for family clustering and a score test to indicate the overall significance for allelic or genotype associations. A stepwise logistic-regression procedure $^{49}$ was used to evaluate the relative importance of variants at the different sites within SLC11A1. Score tests were used to compare models in which the main effects for both loci are modelled with one in which the main effects at the primary locus only are included. Robust TDT and case/pseudo-control statistical tests implemented within Stata were developed by Heather Cordell and David Clayton at the Cambridge Institute for Medical Research, and are available at http://www-gene.cimr.cam.ac.uk/clayton/software/.

\section{Linkage disequilibrium}

Linkage disequilibrium between pairs of markers across SLC11A1 was determined using Hedrick's definition of Lewontin's $D^{\prime}$ statistic. $^{50}$

\section{Sequence analysis}

Direct cycle sequence analysis was performed on DNA samples isolated from 29 cases ( 25 for exon 4 a) from 27 families, and seven unaffected (two children, five adults), used in the linkage and association studies. The affected individuals were selected from a subset of families that showed the highest LOD scores for linkage to SLC11A1. Separate PCR assays were designed to amplify the 15 exons, intron 1 and all the intron/exon boundaries of SLC11A1, the region of intron 4 (nt 3046-3503) around and including alternatively spliced exon $4 \mathrm{a}^{51}$ (nt $3191-3264$ ), $\sim 600 \mathrm{bp}$ of sequence upstream of the transcription start site and $819 \mathrm{bp}$ of sequence downstream of the TAG stop codon. The TOPO TA Cloning ${ }^{\circledR}$ kit (Invitrogen, living science) was used to clone PCR-amplified products to facilitate sequence analysis of the 58 individual chromosomes, especially through the promoter region repeats. However, it was not possible to determine whether each new SNP was in cis or trans to SNPs identified on other PCR products in the same individual.

\section{Results \\ Linkage analysis}

A breakdown of family structures for the 59 multicase families used in this study is given in Table 1 . Allele frequencies for the SLC11A1 and D2S1471 loci derived from genetically independent individuals in the families are shown in Table 2. Multipoint nonparametric linkage analysis in ALLEGRO (Table 3$)$ provides evidence $\left(Z_{\mathrm{Ir}_{\text {pars }}}\right.$ scores $2.55-2.38 ; 0.008 \leqslant P \leqslant 0.012$; information content 0.88 ) for linkage between VL and markers across SLC11A1, dropping away at $D 2 S 1471\left(Z_{\mathrm{Ir}_{\text {pairs }}}\right.$ score $1.99 ; P=0.028$;

Table 3 Multipoint nonparametric linkage analysis using the $S_{\text {pairs }}$ function in ALLEGRO ${ }^{44}$ to examine linkage beween the VL phenotype and markers across the SLC11A1 and adjacent $D 251471$ region

\begin{tabular}{lcccc}
\hline Marker & LOD score & $Z_{\text {Ir }}$ score & $P$ & $\begin{array}{c}\text { Information } \\
\text { content }\end{array}$ \\
\hline$(\mathrm{GT})_{n}$ & 1.41 & 2.55 & 0.008 & 0.88 \\
274C/T & 1.40 & 2.54 & 0.008 & 0.88 \\
469+14G/C & 1.40 & 2.54 & 0.008 & 0.87 \\
D543N & 1.24 & 2.39 & 0.012 & 0.88 \\
3'UTR TGTG & 1.23 & 2.38 & 0.012 & 0.88 \\
3'UTR CAAA & 1.23 & 2.38 & 0.012 & 0.88 \\
D2S1471 & 0.86 & 1.99 & 0.028 & 0.88 \\
\hline
\end{tabular}

Allele-sharing LOD and $Z_{\mathrm{Ir}}$ scores, with associated $P$-values and information content, are shown. 
information content 0.88 ) lying $68 \mathrm{~kb}$ distal (telomeric) to the $3^{\prime}$ end of SLC11A1.

\section{Family-based allelic association}

Extended transmission disequilibrium testing (ETDT) ${ }^{47}$ for single markers implemented within TDTPHASE ${ }^{48}$ showed significant global associations (Table 4a) for the $5^{\prime}$ promoter $\left(\mathrm{GT}_{n}\right)$ and intragenic single-nucleotide polymorphisms (SNPs) at $274 \mathrm{C} / \mathrm{T}$ and $469+14 \mathrm{G} / \mathrm{C}$, but not for the $3^{\prime}$ exon 15 SNP D543N, the $3^{\prime} \mathrm{UTR}$ insertion/ deletion (IN/DELs) polymorphisms, or for the D2S1471 microsatellite lying $\sim 68 \mathrm{~kb}$ distal to SLC11A1. Single-point
TDT $P$-values at $274 \mathrm{C} / \mathrm{T}$ and $469+14 \mathrm{G} / \mathrm{C}$ retained significance after correcting for family clustering using TDT with a robust sandwich estimator for the variance (Wald $\chi^{2}$ with $1 \mathrm{df}=5.59, P=0.0171$ for $274 \mathrm{C} / \mathrm{T}$; Wald $\chi^{2}$ with $1 \mathrm{df}=5.56$, $P=0.0184$ for $469+14 \mathrm{G} / \mathrm{C})$, that is, markers within SLC11A1 show true allelic association with disease in the presence of linkage. Significant associations for $5^{\prime}$ markers at SLC11A1 were supported by the case/pseudo-control logistic regression analysis (Table $5 \mathrm{a}$ ) that showed significant allelic associations at the $\mathrm{GT}_{n}$ repeat, as well as for the $274 \mathrm{C} / \mathrm{T}$ and $469+14 \mathrm{G} / \mathrm{C}$ biallelic markers. A borderline significant $\chi^{2}$ test comparing allele-wise $(1 \mathrm{df})$ and

Table 4 (a) Global allelewise significance levels ( $P$-values) for family-based SLC11A1 allelic and haplotype associations with VL obtained using ETDT ${ }^{47}$ implemented within TDTPHASE. ${ }^{48}$ (b) Specific haplotype associations for the three $5^{\prime}$ markers $\left(\mathrm{GT}_{n}-274 \mathrm{C} / \mathrm{T}-469+14 \mathrm{C} / \mathrm{G}\right)$ showing significant individual marker and haplotype global associations between SLC11A1 and $\mathrm{VL}$ in Sudan

(a)

\begin{tabular}{|c|c|c|c|c|c|c|c|}
\hline No. of markers & $G T_{n}$ & $274 C / T$ & $469+14 C / G$ & D543N & 3'UTRTGTG & $3^{\prime} U T R C A A A$ & $D 2 S 1471$ \\
\hline \multirow{3}{*}{$\begin{array}{l}\text { One } \\
\text { Two }\end{array}$} & 0.0145 & 0.0037 & 0.0049 & 0.1972 & 0.5310 & 0.8785 & 0.0816 \\
\hline & & & & & & & \\
\hline & & \multicolumn{2}{|c|}{0.0115} & & & & \\
\hline
\end{tabular}

0.0367

0.1655

0.2007

Three

0.0089

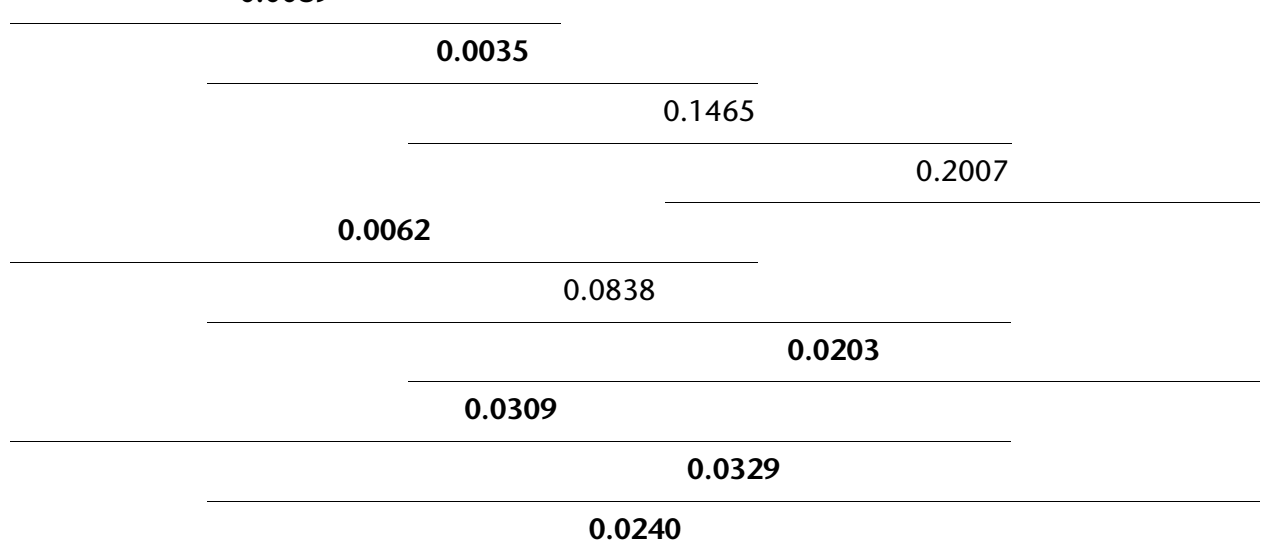

(b)

\begin{tabular}{lccccc}
\hline Haplotypes & $T$ & $N T$ & $\% T$ & $\chi 2(1)$ & $P$ \\
\hline Disease associated & 64 & 34 & 65 & 8.80 & $\mathbf{0 . 0 0 3}$ \\
$3-2-1$ & 6 & 1 & 86 & 3.57 & $\mathbf{0 . 0 5 8}$ \\
$4-1-2^{\text {a }}$ & 8 & 24 & 25 & 7.93 & $\mathbf{0 . 0 0 5}$ \\
Disease protective & & & & \\
$2-1-2$ & & 24 & & & \\
\hline
\end{tabular}

Underlining in (a) indicates which groups of two, three, four, five or six markers were being haplotyped. Bold indicates $P$ values that are significant $(<0.05)$. $T=$ number of transmitted haplotypes; $N T=$ number of nontransmitted haplotypes. \% $=$ per cent transmitted. $\chi_{(1)}^{2}=\mathrm{Chi}$-squared with 1 degree of freedom; $P=P$-value. ${ }^{a}$ Allele 4 of $\mathrm{GT}_{n}$ - all transmissions from one extended pedigree. 
Table 5 'Case/pseudo-control' allelic association testing ${ }^{49}$ for SLC11A1 markers and VL. (a) Shows P-values for conditional logistic regression analysis for allelic ( $1 \mathrm{df}$ tests) and genotype ( $2 \mathrm{df}$ tests) associations at the six polymorphic markers. A significant $\chi^{2}$ test comparing the difference between 1 and 2 df tests indicates dominance rather than a multiplicative model. (b) Shows the results of score tests of the main effects of a locus in a forward stepwise regression procedure. Robust variance estimates to control for family clustering were used throughout

(a)

\begin{tabular}{|c|c|c|c|c|c|c|c|c|}
\hline Test & $G T_{n}$ allele 2 & $G T_{n}$ allele 3 & $G T_{n}{ }^{a}$ allele 4 & $274 \mathrm{C} / T^{\mathrm{b}}$ & $469+14 G / C^{b}$ & $D 543 N^{b}$ & $3^{\prime} U T R T G T G^{\mathrm{b}}$ & $3^{\prime}$ UTR CAAA \\
\hline it & & & & & & & & \\
\hline $1 \mathrm{df}$ & 0.1176 & 0.1273 & 0.0119 & 0.0148 & 0.0039 & 0.3219 & 0.4820 & 0.5208 \\
\hline $2 \mathrm{df}$ & 0.2955 & 0.1239 & - & - & - & - & - & 0.6986 \\
\hline Dominance test & 0.4294 & 0.0535 & - & - & - & - & - & 0.7728 \\
\hline
\end{tabular}

(b)

\begin{tabular}{lllcl}
\hline \multirow{2}{*}{ Null model } & Alternative model & $\chi^{2}$ & Test statistic \\
& $\mathrm{GT}_{n}$ a3 & $d f$ & $P$ \\
\hline & $274^{\mathrm{c}}$ & 3.76 & 1 & $\mathbf{0 . 0 5 2 5}$ \\
$\mathrm{GT}_{n}$ a3 & $469^{\mathrm{c}}$ & 6.06 & 1 & $\mathbf{0 . 0 1 3 8}$ \\
274 & $\mathrm{GT}_{n} \mathrm{a} 3+274$ & 9.03 & 1 & $\mathbf{0 . 0 0 2 7}$ \\
$\mathrm{GT}_{n}$ a3 & $274+\mathrm{GT}_{n}$ a3 & 5.56 & 1 & $\mathbf{0 . 0 1 8 4}$ \\
469 & $\mathrm{GT}_{n} \mathrm{a} 3+469$ & 2.45 & 1 & 0.1176 \\
274 & $469+\mathrm{GT}_{n}$ a3 & 1.60 & 1 & $\mathbf{0 . 0 0 5 8}$ \\
469 & $274+469$ & 1.70 & 1 & 0.1919 \\
& $469+274$ & 4.29 & 1 & $\mathbf{0 . 0 3 8 3}$ \\
\hline
\end{tabular}

${ }^{a}$ Allele 4 of $\mathrm{GT}_{n}$ found in heterozygous condition only, hence only $1 \mathrm{df}$ test valid. ${ }^{\mathrm{b}}$ Only two different genotypes observed in cases, hence only $1 \mathrm{df}$ test valid. Dominance effect only observed with the $\mathrm{GT}_{n} .{ }^{\circ}$ These test statistics differ slightly from the $1 \mathrm{df}$ test data in Table $3 \mathrm{a}$, because only individuals for whom all the three markers were fully typed could be included in this stepwise analysis. Bold indicates significant $P$ value $(\leqslant 0.05)$.

genotype-wise $(2 \mathrm{df})$ tests for $\mathrm{GT}_{n}$ allele 3 indicates dominance rather than a simple multiplicative (ie both alleles contributing equally) model. The genotype-relative risks for carrying one or two copies of allele 3 at the $\mathrm{GT}_{n}$ were 9.63 (95\% CI 1.07-86.96; $P=0.044)$ and $10.20(95 \%$ CI 1.06-98.16; $P=0.044)$, respectively. The allele-wise relative risk associated with allele 4 at the $\mathrm{GT}_{n}$ was 6.00 (95\% CI 1.50-23.99; $P=0.011$ ), with allele 2 at 274C/T was 2.00 (95\% CI 1.16-3.44; $P=0.012)$, and with allele 2 at $469+14 \mathrm{G} / \mathrm{C}$ was 0.38 (95\% CI $0.20-0.71 ; P=0.003)$. No dominance effects were observed for $274 \mathrm{C} / \mathrm{T}$ and $469+14 \mathrm{G} / \mathrm{C}$. TDTPHASE (Table $4 \mathrm{a}$ ) showed significant $(0.011 \leqslant P \leqslant 0.0089)$ global associations for $5^{\prime}$ (ie $\mathrm{GT}_{n^{-}}$ $274 \mathrm{C} / \mathrm{T}-469+14 \mathrm{G} / \mathrm{C}$ ) intragenic haplotypes and for haplotypes extending from $5^{\prime}$ to $3^{\prime}$ markers within SLC11A1 $(0.006 \leqslant P \leqslant 0.033)$, but not for haplotypes involving only the $3^{\prime}$ markers (ie D543N-TGTG-CAAA). The $5^{\prime}$ haplotype associations involved a significant bias in the transmission of haplotype 3-2-1 $(P=0.003)$ to the affected offspring, and significant protection $(P=0.005)$ associated with haplotype 2-1-2 (Table $4 \mathrm{~b}$ ). Bias (borderline significant) in transmission of the haplotype 4-1-2 to the affected offspring occurred in a single extended pedigree.

Of the markers associated with VL in the $5^{\prime}$ region of $S L C 11 A 1$, only the promoter $\mathrm{GT}_{n}$ is known to be functional in regulating the expression of SLC11A $1^{52}$ and yet alleles at this locus were associated with only borderline significance. To determine whether the $\mathrm{GT}_{n}$ contributed significant main effects to the haplotype associations observed, we carried out tests (Table 5b) to determine the main effects at each locus in a forward stepwise logistic regression procedure. ${ }^{49}$ For this stepwise analysis, we compared the contribution of the main disease-associated allele 3 at the $\mathrm{GT}_{n}$ with the other two biallelic markers. At the first stage (rows $1-3$ ), the $\mathrm{GT}_{n}$ (borderline, $P=0.05$ ), $274 \mathrm{C} / \mathrm{T}(P=0.01)$ and $469+14 \mathrm{G} / \mathrm{C}(P=0.003)$ are all significant when included in the model on their own, that is, without accounting for effects at other loci. Once the $\mathrm{GT}_{n}$ is included in the model, both the 274C/T (row 4) and the $469+14 \mathrm{G} / \mathrm{C}$ (row 6 ) add significant main effects. Once the $274 \mathrm{C} / \mathrm{T}$ is included, only the $469+14 \mathrm{G} / \mathrm{C}$ (row 8) and not the $\mathrm{GT}_{n}$ (row 5) has a main effect. Once the $469+14 \mathrm{G} /$ $\mathrm{C}$ is included, neither the $\mathrm{GT}_{n}$ (row 7) nor the 274C/T (row 9) have main effects. Overall, this stepwise analysis indicates that all of the association between SLC11A1 and the disease can be accounted for by the $469+14 \mathrm{G} / \mathrm{C}$ polymorphism. This is consistent with the observation (Table 6) that the $469+14 \mathrm{G} / \mathrm{C}$ is in strong linkage disequilibrium with both the $\mathrm{GT}_{n}\left(D^{\prime}=0.7136\right)$ and the $274 \mathrm{C} / \mathrm{T}\left(D^{\prime}=0.8919\right)$, even though the latter are not in strong linkage disequilibrium with each other. 
Table 6 Pairwise linkage disequilibrium between markers across SLC11A1 calculated using the Lewontin's $D^{\prime 50}$

\begin{tabular}{|c|c|c|c|c|c|c|}
\hline \multicolumn{7}{|l|}{ 3'UTR CAAA } \\
\hline 3'UTR TGTG & & & & & 0 & 0.7353 \\
\hline D543N & & & & 0 & 0.9140 & 1.000 \\
\hline $469+14 G / C$ & & & 0 & 0.6436 & 0.6833 & 0.6631 \\
\hline $274 \mathrm{C} / \mathrm{T}$ & & 0 & 0.8919 & 0.4717 & 0.3547 & 0.0767 \\
\hline $\mathrm{GT}_{n}$ & 0 & 0.2755 & 0.7136 & 0.4400 & 0.4960 & 0.1227 \\
\hline & $\mathrm{GT}_{n}$ & $274 \mathrm{C} / \mathrm{T}$ & $469+14 G / C$ & D543N & 3'UTR TGTG & 3'UTR CAAA \\
\hline
\end{tabular}

Bold indicates $5^{\prime}$ markers in strong linkage disequilibrium.

Table 7 Results of sequence analysis across $\sim 600 \mathrm{bp}$ upstream of the transcription start site, all 15 exons, intron 1 and all intron/exon boundaries, and $819 \mathrm{bp}$ downstream of the TAG stop codon in 29 cases from 27 of the families and seven unaffected individuals, used in the linkage and association studies

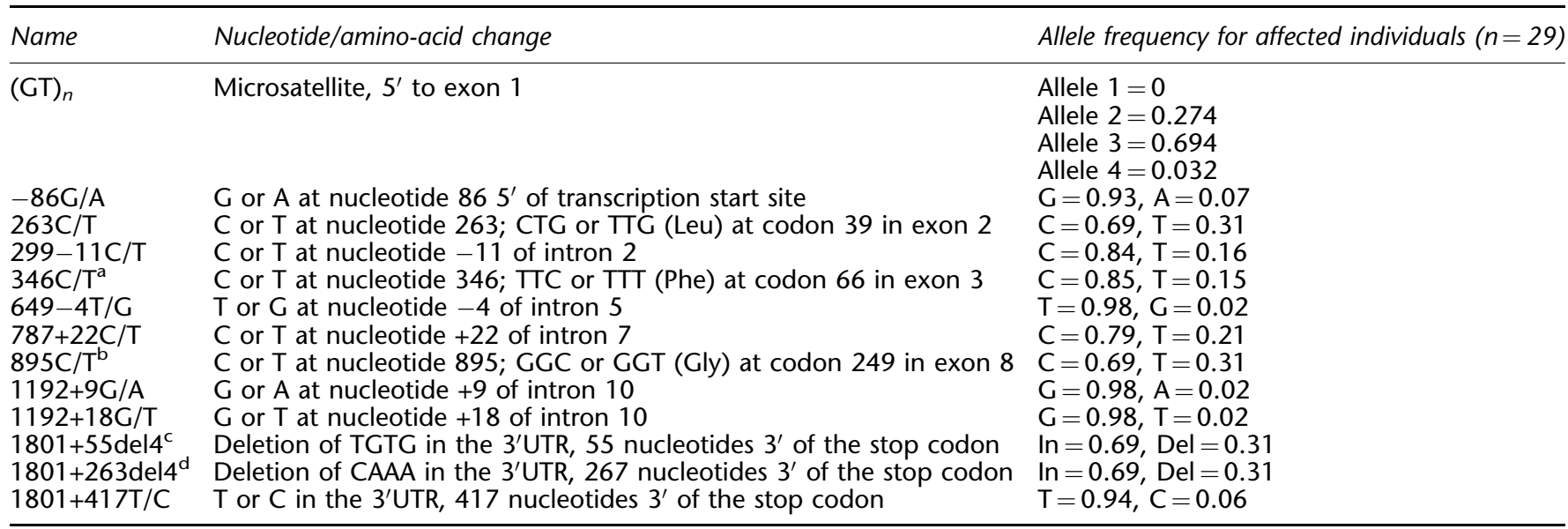

Details of novel SNPs are shown, together with allele frequencies in the 29 cases for the previously identified ${ }^{40,42,43}$ polymorphic markers. To conform with standard notation, all the previously identified and new SNPs are named in relation to the transcription start site located $148 \mathrm{bp} 5^{\prime}$ of the methionine start codon. ${ }^{42}$ Previous notations $\mathrm{s}^{40,43}$ were assigned relative to an arbitrary site $76 \mathrm{bp}$ upstream of the methionine start codon. ${ }^{2}$ Previously $274 \mathrm{C} / \mathrm{T}^{40}$ b Previously $823 \mathrm{C} / \mathrm{T}^{40}$ CPreviously $1729+55 \mathrm{del} 4 .{ }^{40}$ dPreviously 1992 (CAAA) $n .{ }^{43}$

\section{Sequence analysis}

The results of stepwise regression analysis for markers across the $5^{\prime}$ region of SLC11A1 suggested that all of the association with VL is accounted for by the polymorphism at $469+14 \mathrm{G} / \mathrm{C}$. Although the functional $\mathrm{GT}_{n}$ might contribute to the overall $469+14 \mathrm{G} / \mathrm{C}$ effect, the results suggest that other functional polymorphisms in linkage disequilibrium with $469+14 \mathrm{G} / \mathrm{C}$ must be present and contribute. Since the intronic $469+14 \mathrm{G} / \mathrm{C}$ SNP is itself unlikely to influence function, further sequence analysis was required to determine whether novel polymorphisms occur within the Masalit populations of eastern Sudan, which could account for this association. To this end, we sequenced $\sim 600 \mathrm{bp}$ upstream of the transcription start site, intron 1, all 15 exons and intron/exon boundaries, the region of intron 4 containing the alternatively spliced exon $4 \mathrm{a}$, and $819 \mathrm{bp}$ downstream of the TAG stop codon in 29 cases from 27 families and seven unaffected individuals used in the linkage and association studies. Table 7 shows the new SNPs identified, together with allele frequencies in the 29 cases for the previously identified ${ }^{40,42,43}$ polymorphic markers that were included in the sequence analysis. To conform with standard notation, all previously identified and new SNPs are named in relation to the transcription start site located $148 \mathrm{bp} 5^{\prime}$ of the methionine start codon. ${ }^{42}$ Previous notations ${ }^{40,43}$ were assigned relative to an arbitrary site $76 \mathrm{bp}$ upstream of the methionine start codon. Eight new SNPs were identified (Table 7), only one of which occurred in the coding region at codon 39 in exon 2. This was a silent mutation, a C-to-T substitution that resulted in a synonymous amino-acid substitution, which would not cause a functional change in the SLC11A1 protein. Five other SNPs occurred at the intron/ exon boundaries, and one in the $3^{\prime} U T R$. All of these were again unlikely to mediate functional changes. Sequence analysis within intron 4 confirmed the presence of exon $4 \mathrm{a}$ in this Sudanese population, but no variants that might relate through linkage disequilibrium to the significance associated with the intron 4 variant $469+14 \mathrm{G} / \mathrm{C}$ were found. One new SNP 86 nucleotide $5^{\prime}$ of the transcription start site (ie position $-86 \mathrm{bp}$ ) was located within a putative nuclear factor kappa B (NF $\kappa$ B)-binding site, which could be functional in the regulation of gene expression. The wildtype allele shared seven out of 10 nucleotides in the $\mathrm{NF} \kappa \mathrm{B}$ 
known consensus GGGRHTYYCC (where according to the universal genetic code, $\mathrm{R}=\mathrm{G}$ or $\mathrm{A} ; \mathrm{H}=\mathrm{C}$, $\mathrm{A}$ or $\mathrm{T}$ and $\mathrm{Y}=\mathrm{C}$ or $\mathrm{T}),{ }^{53}$ while the mutant shared only six from 10 nucleotides. This variant occurred in only four (0.06) of the 58 chromosomes sequenced from four affected individuals (ie heterozygous in all), and so was unlikely to account for disease susceptibility on its own. The variant allele occurred in cis with allele 3 of the previously identified $\mathrm{GT}_{n}$ polymorphism in one affected individual and in cis with allele 2 for three affected individuals.

\section{Discussion}

The data presented here provide evidence (maximum multipoint $Z_{\mathrm{lr}}=2.55 ; \quad P=0.008$ ) for linkage between SLC11A1 and susceptibility to VL in members of the Masalit tribe in eastern Sudan, thus replicating the recent report $^{54}$ of linkage (maximum multipoint LOD score $=1.08 ; P=0.01$ ) between $S L C 11 A 1$ and VL in the related Aringa ethnic group to the north of our study population in Sudan. Our study extended this finding using family-based TDT and logistic regression analysis to demonstrate the allelic association with $5^{\prime}\left(\mathrm{GT}_{n}, 274 \mathrm{C} / \mathrm{T}\right.$, $469+14 \mathrm{G} / \mathrm{C}$ ) but not $3^{\prime}$ (D543N, 3'UTR TGTG, 3'UTR CAAA) markers within SLC11A1. In a previous casecontrol analysis, Bellamy et $a l^{26}$ found a significant association between four intragenic SLC11A1 polymorphisms $\left(\mathrm{CA}_{n}=\mathrm{GT}_{n}, \mathrm{INT} 4=469+14 \mathrm{G} / \mathrm{C}, \mathrm{D} 543 \mathrm{~N}\right.$ and $3^{\prime} \mathrm{UTR}$ TGTG) and susceptibility to pulmonary tuberculosis in The Gambia. As with our study in Sudan, the two polymorphic markers in the $5^{\prime}$ region of the gene $\left(\mathrm{CA}_{n}\right.$ and INT4) were in strong linkage disequilibrium, as were the two markers in the $3^{\prime}$ region (D543N and $3^{\prime}$ UTR TGTG), but markers in the $5^{\prime}$ region were not in linkage disequilibrium with the markers in the $3^{\prime}$ region. Since they had observed significant associations at all four markers, they concluded that separate polymorphisms in the $5^{\prime}$ and $3^{\prime}$ regions of the gene acted independently to control susceptibility to tuberculosis. $^{26}$ In Sudan, we have failed to find any evidence either for association with markers in the $3^{\prime}$ region of SLC11A1 and VL, or any novel change of function mutations across this region. Nor did we find evidence for any novel (functional) variant in or around the alternatively spliced exon $4 \mathrm{a}$ that might account, through linkage disequilibrium, for the main effects observed at $469+\mathrm{G} / \mathrm{C}$ using stepwise logistic regression analysis. Previous studies $^{51}$ have shown that exon $4 \mathrm{a}$, encoded by an Alu element within intron 4 , is transcribed in vivo but would introduce a termination codon in exon $\mathrm{V}$, resulting in a truncated and hence nonfunctional SLC11A1 protein. At the mRNA level, the ratio of transcripts with/without exon 4a was 1:5 in macrophage cell lines. ${ }^{51}$ Hence, we hypothesised that any variant (eg elimination of the splice acceptor site for transcription of the alternatively spliced product) that caused a change in this ratio might influence the amount of functional SLC11A1 protein expressed. If such a variant occurs, it is not encoded at the site of exon $4 \mathrm{a}$. However, variants in the promoter in linkage disequilibrium with $469+14 \mathrm{G} / \mathrm{C}$ could be responsible for regulating the level of normal SLC11A1 transcribed, and/or the ratio of normal to alternatively spliced product. In our study, there was no novel change of function mutations in the $5^{\prime}$ coding region or intron 1 of SLC11A1 that would, on its own, account for the association with $469+14 \mathrm{G} / \mathrm{C}$. This suggests that there are further functional polymorphisms upstream of the $\mathrm{GT}_{n}$ in linkage disequilibrium with $469+\mathrm{G} / \mathrm{C}$ that might contribute to these main effects. This could include the potentially functional variant at 86G/A, although the low frequency of this novel allele means that it is unlikely to account for all of the association with $469+\mathrm{G} / \mathrm{C}$ that we have observed. It is also possible that linkage disequilibrium might extend $230 \mathrm{~kb}$ upstream to the gene (IL8RA) encoding the receptor for interleukin 8, although confirmation of the role of Slc11a1 in susceptibility to VL using gene knockout in mice ${ }^{20}$ makes this the most likely candidate for our associations with disease in man. Work is in progress to sequence a larger region of upstream sequence in the SLC11A1 promoter, and to carry out functional reporter gene analysis of the $-86 \mathrm{G} / \mathrm{A}$ variant. For the moment, we conclude that the previously identified $^{40,42}$ promoter region $\mathrm{GT}_{n}$ polymorphism remains the only functional $^{52}$ variant identified to date at SLC11A1. Since it is in strong linkage disequilibrium with $469+14 \mathrm{G}$ / $\mathrm{C}$, it likely makes a significant contribution to the haplotype associations observed and some discussion of its role is therefore of interest.

Firstly, it was of interest that the main disease-associated haplotype carried allele 3 at the $\mathrm{GT}_{n}$, given the previous demonstration $^{52}$ that this allele drives high levels of reporter gene (and hence SLC11A1) expression. These reporter gene constructs carried the four allelic variants of the $\mathrm{GT}_{n}$ on constructs that incorporated $571-587 \mathrm{bp}$ of promoter sequence $5^{\prime}$ of the ATG initiation codon. ${ }^{52}$ Although these constructs differed only at the $\mathrm{GT}_{n}$ repeat, it is possible that other variants upstream of the $\mathrm{GT}_{n}$ may modulate the promoter activity of allele 3 in macrophages in vivo. Nevertheless, in our previous studies ${ }^{31,37}$ examining the role of this polymorphism in determining susceptibility to autoimmune $v s$ infectious disease susceptibility, we proposed that the high-expressing allele 3 would be associated with proinflammatory responses and autoimmune disease, while the low-expressing allele 2 would be associated with low antimicrobial activity and susceptibility to infectious disease. For those studies in which the promoter $\mathrm{GT}_{n}$ has been studied, this hypothesis has held true in relation to susceptibility to pulmonary tuberculosis associated with allele $2^{24,26,28}$ and autoimmune diseases associated with allele $3 .^{31,33,36,37,55}$ In relation to infectious disease, the one exception to date is HIV, where disease was 
associated with allele $3 .^{30}$ Given the propensity of tumour necrosis factor $\alpha(\mathrm{TNF} \alpha)$ to drive high levels of HIV expression via $\mathrm{NF} \kappa \mathrm{B}$ signalling, ${ }^{56}$ association with a high SLC11A1-expressing allele is not surprising. Similarly, VL is known to be associated with a high proinflammatory TNF $\alpha$ response and cachexia. ${ }^{57}$ In The Sudan, it is possible that high levels of expression of SLC11A1 driven by allele 3 have a detrimental effect on VL susceptibility by causing a high proinflammatory response. Conversely, in a recent study in The Gambia, ${ }^{58}$ we demonstrated that the tuberculosis-associated allele 2 at the $\mathrm{GT}_{n}$ repeat was associated with high anti-inflammatory interleukin 10 responses. Hence, the delicate balance between the positive requirement for macrophage activation and antimicrobial activity and the negative effect of proinflammatory $\mathrm{TNF} \alpha$, both of which are pleiotropic effects of $S L C 11 A 1,{ }^{59,60}$ appear to occur across the spectrum of infectious diseases associated with polymorphism SLC11A1 and not just in comparing infectious $v s$ autoimmune disease susceptibility. Interestingly, in one family, disease was associated with the low-expressing ${ }^{52}$ allele 4 of the SLC11A1 $\mathrm{GT}_{n}$ polymorphism, even though it was carried on an otherwise protective 1-2 haplotype for $274 \mathrm{C} / \mathrm{T}-469+14 \mathrm{G} / \mathrm{C}$. Whether, in this case, individuals are susceptible to VL because they fail to express SLC11A1, or because allele 4 was on a haplotype with other functional polymorphisms in the SLC11A1 promoter, will require further investigation. Studies are in progress to examine SLC11A1 expression at the RNA and protein levels in individuals carrying the different SLC11A1 haplotypes that we have seen associated with disease in this population. We will also determine whether the $-86 \mathrm{G} / \mathrm{A}$ variant, or other variants upstream in the promoter region, modulate the function of the $\mathrm{GT}_{n}$ repeat polymorphism.

Overall, our results have shown that SLC11A1 is associated with susceptibility to VL in eastern Sudan. Further work is underway to determine the precise functional basis to disease-promoting variants in the SLC11A1 gene, and to determine which of the many pleiotropic effects of the gene most affects disease phenotype in man. This we hope will contribute to a better understanding of the molecular basis to disease susceptibility, and the development of therapies appropriate to the susceptible individuals in this high-incidence population.

\section{Acknowledgements}

We thank the people of Sudan, and the field and laboratory teams in Sudan, who contributed to this study. Huirong Jiang and Chris Lowe kindly helped with elements of the sequencing process. The work was supported by grants from the Wellcome Trust and the UNDP/World Bank/WHO Special Programme for Research and Training in Tropical Diseases (TDR).

\section{References}

1 De Beer P, Harith AE, van Grootheest M, Winkler A: Outbreak of kala-azar in The Sudan. Lancet 1990; 335: 224.
2 Perea WA, Moren A, Ancelle T, Sondorp E: Epidemic of visceral leishmaniasis in southern Sudan. Lancet 1989; ii: 1222-1223.

3 Zijlstra EE, El Hassan AM, Ismael A, Ghalib HW: Endemic kalaazar in Eastern Sudan, a longitudinal study on the incidence of clinical and subclinical infection and post-kala-azar dermal leishmaniasis. Am J Trop Med Hyg 1994; 51: 826-836.

4 El Hassan AM, Zilijstra EE, Ismael A, Ghalib HW: Recent observations on the epidemiology of kala-azar in the eastern and central states of The Sudan. Trop Geograph Med 1995; 47: $151-156$.

5 Ibrahim ME, Lambson B, Yousif AO et al: Kala-azar in a high transmission focus: an ethnic and geographic dimension. Am J Trop Med Hyg 1999; 61: 941-944.

6 Bradley DJ, Kirkley J: Variation in susceptibility of mouse strains to Leishmania donovani infection. Trans R Soc Trop Med Hyg 1972; 66: $527-528$.

7 Bradley DJ: Genetic control of natural resistance to Leishmania donovani. Nature 1974; 250: 353-354.

8 Bradley DJ, Kirkley J: Regulation of Leishmania populations within the host. I. The variable course of Leishmania donovani infections in mice. Clin Exp Immunol 1977; 30: 119-129.

9 Bradley DJ: Regulation of Leishmania populations within the host. II. Genetic control of acute susceptibility of mice to Leishmania donovani infection. Clin Exp Immunol 1977; 30: 130-140.

10 Bradley DJ, Taylor BA, Blackwell J, Evans EP, Freeman J: Regulation of Leishmania populations within the host. III. Mapping of the locus controlling susceptibility to visceral leishmaniasis in the mouse. Clin Exp Immunol 1979; 37: 7-14.

11 Plant J, Glynn AA: Natural resistance to Salmonella infection, delayed hypersensitivity and Ir genes in different strains of mice. Nature 1974; 248: 345-347.

12 Plant J, Glynn AA: Genetics of resistance to infection with Salmonella typhimurium in mice. J Infect Dis 1976; 133: 72-78.

13 Plant J, Glynn AA: Locating salmonella resistance gene on mouse Chromosome 1. Clin Exp Immunol 1979; 37: 1-6.

14 Gros P, Skamene E, Forget A: Genetic control of natural resistance to Mycobacterium bovis (BCG) in mice. J Immunol 1981; 127: $2417-2421$

15 Brown IN, Glynn AA, Plant J: Inbred mouse strain resistance to Mycobacterium lepraemurium follows the Ity/Lsh pattern. Immunology 1982; 47: 149-156.

16 Skamene E, Gros P, Forget A, Patel PJ, Nesbitt MN: Regulation of resistance to leprosy by chromosome 1 locus in the mouse. Immunogenetics 1984; 19: 117-124.

17 Goto Y, Buschman E, Skamene E: Regulation of host resistance to Mycobacterium intracellulare in vivo and in vitro by the Bcg gene. Immunogenetics 1989; 30: 218-221.

18 Vidal SM, Malo D, Vogan K, Skamene E, Gros P: Natural resistance to infection with intracellular parasites: isolation of a candidate for Bcg. Cell 1993; 73: 469-485.

19 Goswami T, Bhattacharjee A, Babal P et al: Natural-resistanceassociated macrophage protein 1 is an $\mathrm{H}+$ /bivalent cation antiporter. Biochem J 2001; 354: 511-519.

20 Vidal S, Tremblay ML, Govoni G et al: The $I t y / L s h / B c g$ locus: natural resistance to infection with intracellular parasites is abrogated by disruption of the Nramp1 gene. J Exp Med 1995; 182: $655-666$.

21 Gruenheid S, Pinner E, Desjardins M, Gros P: Natural resistance to infections with intracellular pathogens: The Nramp1 protein is recruited to the membrane of the phagosome. J Exp Med 1997; 185: 717-730.

22 Searle S, Bright NA, Roach TIA et al: Localisation of Nramp1 in macrophages: modulation with activation and infection. J Cell Sci 1998; 111: 2855-2866.

23 Abel L, Sanchez FO, Oberti J et al: Susceptibility to leprosy is linked to the human NRAMP1 gene. I Infect Dis 1998; 177: $133-145$.

24 Shaw M-A, Collins A, Peacock CS et al: Evidence that genetic susceptibility to Mycobacterium tuberculosis in a Brazilian population is under oligogenic control: linkage study of the 
candidate genes NRAMP1 and TNFA. Tuberc Lung Dis 1997; 78: $35-45$.

25 Greenwood CM, Fujiwara TM, Boothroyd LJ et al: Linkage of tuberculosis to chromosome 2q35 loci, including NRAMP1, in a large aboriginal Canadian family. Am J Hum Genet 2000; 67: $405-416$

26 Bellamy R, Ruwende C, Corrah T, McAdam KPWJ, Whittle HC, Hill AVS: Variation in the NRAMP1 gene is associated with susceptibility to tuberculosis in West Africans. N Engl J Med 1998; 338: 640-644.

27 Ryu S, Park YK, Bai GH, Kim SJ, Park SN, Kang S: 3'UTR polymorphisms in the NRAMP1 gene are associated with susceptibility to tuberculosis in Koreans. Int J Tuberc Lung Dis 2000; 4: 577-580.

28 Gao PS, Fujishima S, Mao XQ et al: Genetic variants of NRAMP1 and active tuberculosis in Japanese populations. International Tuberculosis Genetics Team. Clin Genet 2000; 58: 74-76.

29 Cervino AC, Lakiss S, Sow O, Hill AV: Allelic association between the NRAMP1 gene and susceptibility to tuberculosis in GuineaConakry. Ann Hum Genet 2000; 64: 507-512.

30 Marquet S, Sanchez FO, Arias M et al: Variants of the human NRAMP1 gene and altered human immunodeficiency virus infection susceptibility. J Infect Dis 1999; 180: 1521-1525.

31 Shaw M-A, Clayton D, Atkinson SE et al: Linkage of rheumatoid arthritis to the candidate gene NRAMP1 on 2q35. J Med Genet 1996; 33: 672-677.

32 Hofmeister A, Neibergs HL, Pokorny RM, Galanduik S: The natural resistance-associated macrophage protein gene is associated with Crohn's disease. Surgery 1997; 122: 173-179.

33 Esposito L, Hill NJ, Pritchard LE et al: Genetic analysis of chromosome 2 in type 1 diabetes: analysis of putative loci IDDM7, IDDM12, and IDDM13 and candidate genes NRAMP1 and IA-2 and the interleukin-1 gene cluster. IMDIAB Group. Diabetes 1998; 47: 1797-1799.

34 Singal DP, Li J, Zhu Y, Zhang G: NRAMP1 gene polymorphisms in patients with rheumatoid arthritis. Tissue Antigens 2000; 55: $44-47$.

35 Yang YS, Kim SJ, Kim JW, Koh EM: NRAMP1 gene polymorphisms in patients with rheumatoid arthritis in Koreans. J Korean Med Sci 2000; 15: 83-87.

36 Maliarik MJ, Chen KM, Sheffer RG et al: The natural resistanceassociated macrophage protein gene in African Americans with sarcoidosis. Am J Respir Cell Mol Biol 2000; 22: 672-675.

37 Sanjeevi CB, Miller EN, Dabadghao P et al: Polymorphism at NRAMP1 and D2S1471 loci associated with juvenile rheumatoid arthritis. Arthritis Rheum 2000; 43: 1397-1404.

38 Zijlstra EE, el-Hassan AM: Leishmaniasis in Sudan. Visceral leishmaniasis. Trans $R$ Soc Trop Med Hyg 2001; 95 (Suppl 1): S27-S58.

39 Zijlstra EE, el-Hassan AM: Leishmaniasis in Sudan. Post kala-azar dermal leishmaniasis. Trans R Soc Trop Med Hyg 2001; 95 (Suppl 1): S59-S76.

40 Liu J, Fujiwara TM, Buu NT et al: Identification of polymorphisms and sequence variants in human homologue of the mouse natural resistance-associated macrophage protein gene. Am J Hum Genet 1995; 56: 845-853.

41 Copeman JB, Cucca C, Hearne CM et al: Linkage disequilibrium mapping of a type 1 diabetes susceptibility gene (IDDM7) to chromosome 2q31-q33. Nat Genet 1995; 9: 80-85.

42 Blackwell JM, Barton $\mathrm{CH}$, White JK et al: Genomic organization and sequence of the human NRAMP gene: identification and mapping of a promoter region polymorphism. Mol Med 1995; 1 : $194-205$.

43 Buu NT, Cellier M, Gros P, Schurr E: Identification of a highly polymorphic length variant in the $3^{\prime} \mathrm{UTR}$ of NRAMP1. Immunogenetics 1995; 42: 428-429.

44 Gudbjartsson DF, Jonasson K, Frigge ML, Kong A: Allegro, a new computer program for multipoint linkage analysis. Nat Genet 2000; 25: $12-13$

45 Peacock CS, Collins A, Shaw MA et al: Genetic epidemiology of visceral leishmaniasis in northeastern Brazil. Genet Epidemiol 2001; 20: 383-396.

46 Spielman RS, McGinnis RE, Ewens WJ: Transmission test for linkage disequilibrium: the insulin gene region and insulindependent diabetes mellitus (IDDM). Am J Hum Genet 1993; 52: 506-516.

47 Sham PC, Curtis D: An extended transmission/disequilibrium test (TDT) for multi-allele marker loci. Ann Hum Genet 1995; 59: $323-336$.

48 Dudbridge F, Koeleman BP, Todd JA, Clayton DG: Unbiased application of the transmission disequilibrium test to multilocus haplotypes. Am J Hum Genet 2000; 66: 2009-2012.

49 Cordell HJ, Clayton DG: A unified stepwise regression procedure for evaluating the relative effects of polymorphisms within a gene using case/control or family data: application to HLA in type 1 diabetes. Am J Hum Genet 2002; 70: 124-141.

50 Hedrick PW: Gametic disequilibrium measures: proceed with caution. Genetics 1987; 117: 331-341.

51 Cellier M, Govoni G, Vidal S et al: Human natural resistanceassociated macrophage protein: cDNA cloning chromosomal mapping, genomic organization, and tissue-specific expression. J Exp Med 1994; 180: 1741-1752.

52 Searle S, Blackwell JM: Evidence for a functional repeat polymorphism in the promoter of the human NRAMP1 gene that correlates with autoimmune $v s$ infectious disease susceptibility. J Med Genet 1999; 36: 295-299.

53 Lenardo MJ, Baltimore D: NF-kB: a pleiotropic mediator of inducible and tissue-specific gene control. Cell 1989; 58: 227-229.

54 Bucheton B, Abel L, Kheir MM et al: Genetic control of visceral leishmaniasis in a Sudanese population: candidate gene testing indicates a linkage to the NRAMP1 region. Genes Immun 2003; 4: $104-109$.

55 Kotze MJ, de Villiers JN, Rooney RN et al: Analysis of the NRAMP1 gene implicated in iron transport: association with multiple sclerosis and age effects. Blood Cells Mol Dis 2001; 27: 44-53.

56 Swingler S, Morris A, Easton A: Tumour necrosis factor alpha and interleukin-1 beta induce specific subunits of NFKB to bind the HIV-1 enhancer: characterisation of transcription factors controlling human immunodeficiency virus type 1 gene expression in neural cells. Biochem Biophys Res Commun 1994; 203: $623-630$.

57 Barral-Netto M, Badaro R, Barral A et al: Tumor necrosis factor (cachectin) in human visceral leishmaniasis. J Infect Dis 1991; 163: 853-857.

58 Awomoyi AA, Marchant A, Howson JM, McAdam KP, Blackwell JM, Newport MJ: Interleukin-10, polymorphism in SLC11A1 (formerly NRAMP1), and susceptibility to tuberculosis. J Infect Dis 2002; 186: 1804-1814.

59 Blackwell JM, Goswami T, Evans CAW et al: SLC11A1 (formerly NRAMP1) and disease. Cell Microbiol 2001; 3: 773-784.

60 Blackwell JM, Searle S, Goswami T, Miller EN: Understanding the multiple functions of Nramp1. Microbes Infect 2000; 2: 317-321. 